\title{
Intravenous Scopolamine Is Potently Self-Administered in Drug-Naive Mice
}

\author{
Thøger Rasmussen, Ph.D., and Anders Fink-Jensen, M.D.
}

Scopolamine self-administration was investigated in an acute model using drug-naive mice. The mice could selfadminister intravenous infusions contingent on nose poking and were tested in pairs using a contingent and a yoked control mouse. Upon nose poking of the contingent mouse, both mice received an intravenous infusion of either saline or scopolamine (fixed ratio 1 ). An inverted U-shaped unit dose-response curve was seen with the contingent mice. The unit dose at which nose poking of the contingent mice peaked (mean 375 per $30 \mathrm{~min}$ ) was $0.1 \mathrm{mg} / \mathrm{kg} /$ infusion.
Nose poking of yoked control mice also increased dose dependently, but it was significantly lower than that of the contingent mice. The apparent scopolamine-induced dosedependent hyperactivity was, however, unlikely in itself to form the entire basis for the increase in nose poking of the contingent mice. The results demonstrate that scopolamine has acute and reinforcing properties in drug naive mice. [Neuropsychopharmacology 22:97-99, 2000] (C) 1999 American College of Neuropsychopharmacology. Published by Elsevier Science Inc.
KEY WORDS: Scopolamine; Mouse; Drug-naive; Self-administration; Yoked control

Several reports describe abuse potential of herbs or drugs containing muscarinic antagonists. Consumption of thornapple (datura stramonium), which contains scopolamine, atropine, and hyosciamine, was reported to induce hallucinations and euphoria (Greene et al. 1996; Guharoy and Barajas 1991; Hall et al. 1977). Parkinsonism or neuroleptic-induced extrapyramidal side effects have been treated with trihexyphenidyl or benztropine, but nonprescriptive abuse of these drugs has been reported in schizophrenics, borderline personality disorder individuals, or opioid abusers (Fisch 1987; McInnis and Petursson 1984; Rubinstein 1978; Zem-

From the Health Care Discovery, Novo Nordisk A/S, Novo Nordisk Park, DK-2760 Måløv, Denmark.

Address correspondence to: Anders Fink-Jensen, Department of Psychiatry, Bispebjerg Hospital, Bispebjerg bakke 23, DK-2400 København NV, Denmark.

Received April 9, 1999; revised July 9, 1999; accepted July 16, 1999 ishlany et al. 1996). Trihexiphenidyl may induce euphorogenic, energizing, or sedating effects (Fisch 1987; Rubinstein 1978), and benztropine may induce hallucinogenic effects (El-Yousef et al. 1973). Thus, although antimuscarinic abuse potential is recognized, little is known about its possible acute and reinforcing properties. Scopolamine self-administration was demonstrated in a chronic rat model (Glick and Guido 1982), but there is no experimental evidence of possible acute effects of antimuscarinic self-administration. Because drug-naive mice self-administer cocaine, morphine, or nicotine (Kuzmin et al. 1992; Martellotta et al. 1995; Rasmussen and Swedberg 1998), we investigated if scopolamine could be self-administered in this model, suggesting similar acute and reinforcing properties.

\section{MATERIALS AND METHODS}

\section{Drug}

(-)Scopolamine $\mathrm{HBr}$ was obtained from Sigma, St. Louis, MO, USA and dissolved in $0.9 \%$ saline. The solution was prepared immediately before use. 


\section{Animals}

Male Bom:NMRI mice (Bomholtegaard, Ry, Denmark), weighing 20 to $22 \mathrm{~g}$ were used. The mice were housed in a 12 light:12 dark cycle with ad libitum access to food and water. The study was conducted according to internationally accepted principles of the care and use of laboratory animals and approved by the Danish Committee for Animal Research.

\section{Self-Administration Procedure}

The procedure as previously described was used (Rasmussen and Swedberg 1998). Experiments were performed in the mornings. Transparent boxes $(8 \times 8 \times 8$ $\mathrm{cm}$ inner size) fitted with photo cells had a frontal nose poke hole and a posterior vertical chink through which the fixed tails extended. A cannula connected to a tube was inserted into the lateral tail vein. A contingent and a yoked control mouse received an infusion $(1.4 \mu \mathrm{l}, 0.3-\mathrm{s}$ duration, no time out between infusions) of scopolamine or vehicle from a syringe driven by a pump (PHM-100A, Med Associates Inc., East Farfield, VT) upon nose poking of the contingent mouse by interrupting an infrared beam projecting $1 \mathrm{~mm}$ in front of the nose poke hole. Nose poking of the yoked control mouse was recorded but produced no infusions. This mouse served as a control for any drug-induced motoric or psychomotoric effects. A fixed ratio 1 (FR1) schedule was used. After 10 min habituation with no infusions, the self-administration session (30 min) started with an unlimited number of infusions available. Experiments were controlled, and behavior was recorded via an interface (SG 502, Med Associates) using a PC and MED PC 2.09 software (Med Associates). The mice were killed with $\mathrm{CO}_{2}$ immediately after the session.

\section{Data Analysis}

Two-way analysis of variance (ANOVA) was used to test the effect of group (contingent vs. yoked control), dose (including vehicle), and interaction between group and dose. For post hoc testing, Dunnett's test was used to compare single groups of drug mice (contingent or yoked control) and respective vehicle control, and Tukey's test was used to compare single groups of contingent mice and respective yoked control. Statistical tests were performed using SigmaStat ${ }^{\circledR}$ 2.01. Significance levels of 0.05 were used.

\section{RESULTS}

Contingent mice displayed an inverted U-shaped doseresponse curve (Figure 1). There was a significant main effect on nose poking of group, $\mathrm{F}(1,200)=50.29, p<$
.001 , unit dose, $\mathrm{F}(7,200)=12.68, p<.001$, and group by unit dose interaction, $\mathrm{F}(7,200)=3.5, p=.001$. There was significantly higher $(p<005)$ nose poking of contingent scopolamine mice as compared to vehicle control at all unit doses, except $10 \mathrm{mg} / \mathrm{kg} /$ infusion; of yoked control scopolamine mice as compared to vehicle control at the unit dose of $1 \mathrm{mg} / \mathrm{kg}$ only; and of contingent mice as compared to yoked control mice at all unit doses, except $1 \mathrm{mg} / \mathrm{kg} /$ infusion, $10 \mathrm{mg} / \mathrm{kg} /$ infusion, and vehicle. Deaths by self-administration did not occur.

\section{DISCUSSION}

The results demonstrate that scopolamine has acute and reinforcing properties in drug-naive mice. The dose-response curve of contingent mice was similar to findings with cocaine, morphine, or nicotine (Kuzmin et al. 1992; Martellotta et al. 1995; Rasmussen and Swedberg 1998). Albeit the significant group by unit dose interaction demonstrates that increasing dose affected contingent and yoked control mice differently, a dosedependent increase in nose poking of yoked control mice suggests that nose poking of contingent mice was partly attributable to scopolamine-induced hyperactivity. This differs from similar procedures with; for example, cocaine or nicotine (Rasmussen and Swedberg

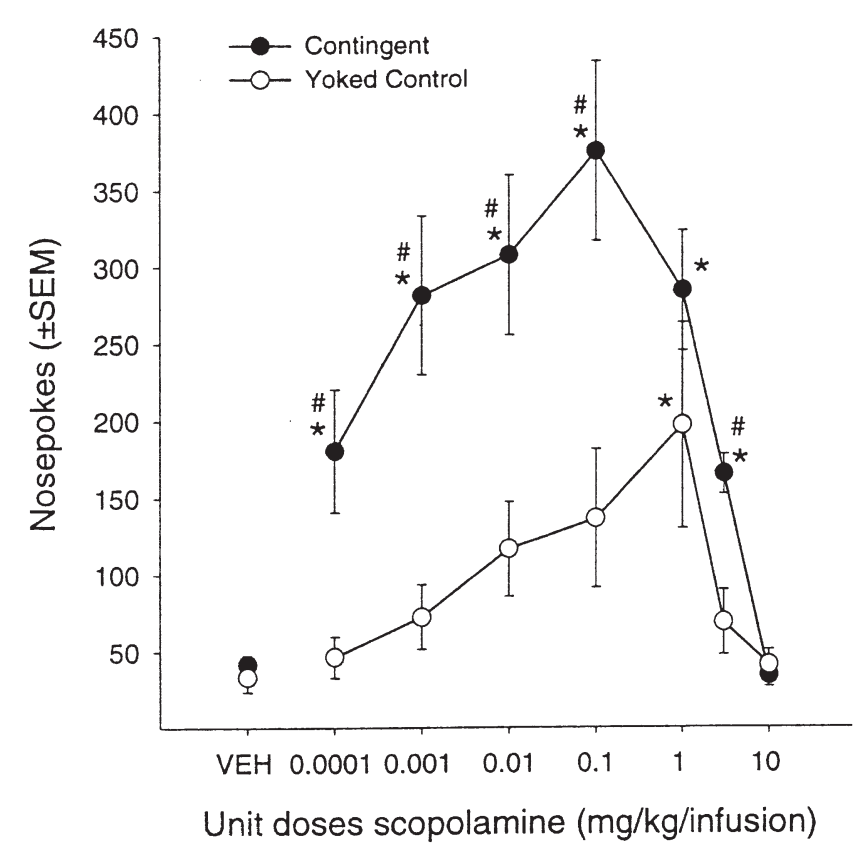

Figure 1. Scopolamine $\mathrm{HBr}$ self-administered in drugnaive mice. Shown are mean number of nose pokes ( \pm SEM) in contingent mice and yoked control mice. ${ }^{*} p<.05$ compared to respective vehicle control mice; \# $p<.05$ compared to yoked control. Numbers of pairs (contingent mouse and yoked control mouse) are 11 to 15 . 
1998), where no such increases were observed, suggesting that even if scopolamine possesses reinforcing properties, it does not belong to the prototypical drugs of this class. Further investigation of its self-administration properties is warranted.

The present results and those of Glick and Guido (1982) are in contrast to the study of Aigner and Balster (1979), where monkeys failed to substitute scopolamine for cocaine self-administration. An explanation for these differences may be that interoceptively compared to cocaine, self-administered scopolamine is weaker or possesses different properties, resulting in lack of selfadministration. In contrast, in the present study or in that of Glick and Guido (1982), the animals had not been challenged with cocaine first.

Early demonstration of scopolamine or benztropine potentiation of apomorphine- induced gnawing in mice suggested a muscarinic-dopaminergic interaction (Scheel-Krüger 1970). Cholinergic Ch5 and Ch6 neurons in and around the pedunculopontine and the laterodorsal tegmental nuclei project to the ventral tegmental area and the substantia nigra, areas containing large numbers of dopamine neurons (Paxinos 1985). Blockade of muscarinic autoreceptors on cholinergic pedunculopontine neurons increases acetylcholine release, thereby enhancing dopaminergic activity in the substantia nigra and ventral tegmental area (Yeomans 1995). These findings imply that muscarinic agonists might have antidopaminergic effects. This was demonstrated by recent investigations showing that several muscarinic agonists, including the novel compound PTAC, exhibit functional central dopamine receptor antagonism (Bymaster et al. 1998; Fink-Jensen et al. 1998).

The present experiments demonstrate that scopolamine self-administration in drug-naive mice has acute and reinforcing properties. These findings add to the understanding of antimuscarinic abuse reported in psychiatric patients. Further investigation of reinforcing and dopaminergic properties of antimuscarinics is warranted.

\section{REFERENCES}

Aigner TG, Balster RL (1979): Rapid substitution procedure for intravenous drug self-administration studies in rhesus monkeys. Pharmacol Biochem Behav 10:105-112

Bymaster FP, Shannon HE, Rasmussen K, DeLapp NW, Mitch CH, Ward JS, Calligaro DO, Ludvigsen TS, Sheardown MJ, Olesen PH, Swedberg MD, Sauerberg P, Fink-Jensen A (1998): Unexpected antipsychotic-like activity with the muscarinic receptor ligand $(5 R, 6 R)$
6-(3-Propylthio-1,2,5- thiadiazol-4-yl)-1-azabicyclo[3.2.1]octane. Eur J Pharmacol 356:109-119

El-Yousef MK, Janowsky DS, Davis JM, Sekerke HJ (1973): Reversal of antiparkinsonian drug toxicity by physostigmine: A controlled study. Am J Psychiat 130:141-145

Fink-Jensen A, Kristensen P, Shannon HE, Calligaro DO, Delapp NW, Whitesitt C, Ward JS, Thomsen C, Rasmussen T, Sheardown MJ, Jeppesen L, Sauerberg P, Bymaster F (1998): Muscarinic agonists exhibit functional antagonism in unilaterally 6-OHDA lesioned rats. NeuroReport 9:3481-3486

Fisch RZ (1987): Trihexyphenidyl abuse: Therapeutic implications for negative symptoms of schizophrenia? Acta Psychiatr Scand 75:91-94

Glick SD, Guido RA (1982): Scopolamine self-administration: Cholinergic involvement in reward mechanisms. Life Sci 31:909-913

Greene GS, Patterson SG, Warner E (1996): Ingestion of Angel's trumpet: An increasingly common source of toxicity. South Med J 89:365-369

Guharoy SR, Barajas M (1991): Atropine intoxication from the ingestion and smoking of Jimson Weed (datura stramonium). Vet Hum Toxicol 33:588-589

Hall RC, Popkin MK, McHenry LE (1977): Angel's trumpet psychosis: A central nervous system anticholinergic syndrome. Am J Psychiat 134:312-314

Kuzmin A, Zvartau E, Gessa L, Martellotta MC, Fratta W (1992): Calcium antagonists isradipine and nimodipine suppress cocaine and morphine self-administration in drug-naive mice. Pharmacol Biochem Behav 41:497-500

Martellotta MC, Kuzmin A, Zvartau E, Cossu G, Gessa GL, Fratta W (1995): Isradipine inhibits nicotine intravenous self-administration in drug-naive mice. Pharmacol Biochem Behav 52:271-274

McInnis M, Petursson H (1984): Trihexyphenidyl dependence. Acta Psychiatr Scand 69:538-342

Paxinos G (ed) (1985): The Rat Nervous System. Sydney, Academic Press

Rasmussen T, Swedberg MDB (1998): Reinforcing effects of nicotinic compounds: Intravenous self-administration in drug-naive mice. Pharmacol Biochem Behav 60: 567573

Rubinstein JS (1978): Abuse of the antiparkinsonism drugs. Feigning of extrapyramidal symptoms to obtain trihexiphenidyl. JAMA 239:2365-2366

Scheel-Krüger J (1970): Central effects of anticholinergic drugs measured by the apomorphine gnawing test in mice. Acta Pharmacol et Toxicol 28:1-16

Yeomans JS (1995): Role of tegmental cholinergic neurons in dopaminergic activation, antimuscarinic psychosis, and schizophrenia. Neuropsychopharmacology 12:3-16

Zemishlany Z, Aizenberg D, Weiner Z, Weizman A (1996): Trihexyphenidyl (Artane) abuse in schizophrenic patients. Int Clin Psychopharmacol 11:199-202 